\title{
Intrinsic Characteristics or Earned It? A Discussion of Firm Attractive Traits and Their Social Media Engagement
}

\author{
Ling Liu \\ Southwestern University of \\ Finance and Economics \\ lingliu@swufe.edu.cn
}

\author{
Aoxuan Liu \\ Southwestern University of \\ Finance and Economics \\ 418113574@qq.com
}

\begin{abstract}
Celebrity firms can gain management, marketing, and financial benefits. Being popular on social media has been proven to have a similar effect. Based on nearly 5,000 actively traded US firms data, this paper discusses the factors that drive users to follow them. The factors were explored from two aspects: the firm's intrinsic characteristics and firm social media engagement. Our results show that there are "engaging traits" that attract users meaning that some firms are 'born-to-be' more popular than others. Luckily for those less attractive firms, they can take advantage of social media engagements to increase their popularity levels and to eventually enjoy marketing and management benefits, because social media engagements have stronger impacts on the level of firm celebrity. However, firm intrinsic characteristics, which have long been ignored by previous studies, might play a bigger role in the future with the diminishing marginal returns of social engagements.
\end{abstract}

\section{Introduction}

Social media is now almost ubiquitous even to business [1,2]. Companies have realized the importance of services like Twitter and Facebook and started to be more active on those platforms. One of the greatest advantages of social media platforms is that they allow users to follow one another, meaning that people can receive real-time updates from accounts that they follow [3]. The action of following another user's account shows the follower's interest and fondness of the followee [4] indicating the level of public popularity. Firm celebrity, which is defined as public attraction and positive emotion for a firm [5], is considered an intangible asset and has positive effects on firm financial performance [6]. Research has suggested that being popular on social media has many benefits from marketing [7], management [8,9], and financial perspectives [10]. Similarly, one market survey [11] reported that $67 \%$ of social media users are more likely to purchase from the brands that they follow, and 79\% of Twitter followers are more likely to recommend the brands that they follow. Thus, a larger number of followers a firm account has not only indicating a wider scale of their information can be spread, but also implying a better sales.

Studies in this area mainly focuse on the effects of firm social media efforts $[8,12,13,14]$ and on how firms should utilize social media $[15,16,17]$. However, little attention has been paid to what defines an attractive firm social media account. Specifically, do people follow a firm's social media account because the firm's intrinsic characteristics or because the firm's social media engagement. For instance, does a user follows a firm's account to have a up-to-date information about their new products or does she enjoy the greeting tweets frequently posted by the firm.

Based on nearly 5,000 actively traded US firms, we find that celebrity firms have distinctive intrinsic characteristics comparing to firms that are less popular on Twitter. For instance, an average top 1\% popular firm has spent nearly 35 times Research \& Development (R\&D) expenses than an average firm. Furthermore, we find that being active on social media has a greater impact on firm popularity than firm intrinsic characteristics. It suggests that the firms that are destined to be less attractive by nature can overcome such kind of weakness, by effectively using social media tools to attract more attention. However, with more and more firms are paying emphasis on social media, the effect of social media engagements might be reduced according to the law of diminishing marginal returns, thus, firm intrinsic traits might play a more important role in the long run.

The main contribution of our study is threefold. First, to the best of our knowledge, our paper is the first to investigate the impact factors behind the differences of firm social media popularity. Second, we identified the intrinsic characteristics that influence the number of social media followers. Lastly, we compared the 
influence of firm intrinsic attractive traits and social media engagement on their level of popularity.

The rest of the paper is organized as follows: Section 2 discusses related work which is followed by 3 introduces our data and models. Section 4 discusses our results and finally, Section 5 concludes the paper.

\section{Related Work}

\subsection{Being Popular on Social Media}

Celebrity firms are those which receive positive attention from the mass public [5, 18]. Traditionally, Conventional mass media plays an important role in directing public attention and emotions regarding firms $[5,6]$. This role has been weakened by social media. The action of following an account on social media platforms typically denotes positive emotions on the part of the follower [10, 19]. Therefore, the number of followers of a firm account can be seen as an indicator of the popularity of that firm. The fact that the most heavily followed social media accounts nearly all involve over-paid celebrities might hint that the most followed firms may receive substantial benefits as well. Thus, the number of followers ${ }^{1}$ a firm's account has on social media can be seen as a proxy of its social media popularity.

Being popular on social media has many benefits from marketing, management, and financial perspectives. One of the most important roles of firm social media accounts is to disseminate firm-related information to investors or business partners. The U.S. Securities and Exchange Commission (SEC) has confirmed that corporations can use social media sites to publish information. Research findings show that the use of Twitter to disseminate corporate news can increase firm market liquidity [9, 8]. Having more followers is also an indication of better financial performance. O'Connor (2012) has drawn attention to the fact that firm social media popularity is significantly related to firm stock prices [7].

Social media popularity may serve as an indicator of brand affinity, customer loyalty, and brand performance $[7,8,10]$. Increasing the number of social media followers is of crucial importance to firm marketing strategies. Most companies adopt social media to promote their products or build brand communities [19]. Firms can publish information on their products through their social media accounts in order to reduce information asymmetry, which will help consumers to make better decisions. Moreover, such information

\footnotetext{
${ }^{1}$ Some platforms, such as Facebook, use other terms, e.g., the number of fans, to denote the same meaning. For the sake of brevity, in the rest of the paper we only use the number of followers.
}

may not only reach their followers, but can also be recommended (through retweeting or other similar actions) to other social media users. Thus, a firm with more followers may be able to disseminate their information and promote their products to a broader audience.

\subsection{Firm Intrinsic Characteristics and Social Media Engagement}

In order to examine what factors are associated with the popularity of firm social media accounts, we adopt Uses and Gratification (U\&G) theory. $U \& G$ theory is an audience-centered approach to understanding why people actively seek out specific forms of media [20, 21]. It suggests that people deliberately select media channels that satisfy their needs [21, 22]. Though the theory was proposed and developed at the mass media scale, U\&G theory is also a suitable approach to study of social media [23, 24, 25, 26]. The core assumption of $U \& G$ theory is that people are not passive consumers of media and that their selection of media is designed to meet their desires [20]. Unlike conventional media, social media allow people to create their own accounts and send messages, which enables firms to manage their own media channels. Public users are then free to choose whom to follow. Based on U\&G theory, these 'following' actions reflect users' purpose-directed choices. Thus, the more needs people have in terms of following a firm's account, the more followers a firm will acquire.

According to U\&G theory, the two needs of users following firms' social media accounts are information and emotional needs $[27,28]$. Concerning information needs, users, whether consumers or other stakeholders, seek out information from firms' social media accounts $[13,29]$. Consumers need information to reduce their uncertainty of products and to make better purchase decisions. Many users prefer to acquire information through social media over Google or news sites [30]. Given that the SEC permits companies to use social media sites, including Facebook and Twitter, to communicate company announcements [31], it is very likely that stakeholders would use social media to monitor firms' activities and financial announcements as well.

Users' information needs toward a firm usually relate to firms' intrinsic characteristics. People who have needs for seeking out information about a firm, usually would have known the firm, e.g., have purchased products from the firm, or at least have heard of the firm, e.g., investors want to acquire more information about a firm before they invest them. Information needs 
are mostly decided by the nature of the firms, such as what kind of products and services they provide, or what industry the firm belonged to. Specifically, firms with "engaging traits", such as, in some industries, or produce specific kind of products, may be naturally more popular than the others. For instance, public users may be more interested in a retail firm than a wholesale firm, and high tech firms, like, Apple and Google, may be more attractive than traditional manufacturing firms. It would be a reasonable inference that some firms are born-to-be more attractive than others, because their engaging intrinsic characteristics. Therefore, we suggest the following hypothesis:

Hypothesis 1. Firm intrinsic characteristics have influence on the level of firm popularity.

Regarding emotional needs, users wish to become more connected to a firm or to their community. Social connection is an Internet-related form of gratification [27]. Social media, as its name suggests, is a tool designed for users to connect with one another. Thus, it is understandable that users drawn to social network sites have strong needs for social connection [32, 33]. Such needs can be significantly fulfilled through firms' social media engagements [23, 32].

Studies have found evidence of how firms' social media efforts, i.e., posts tweets or replies to users' tweets, can enhance and fulfill users' social needs, which in turn has a positive influence on users' social media behaviors [12, 34, 35, 36]. For instance, De Vires et al. (2012) discusses determinants of brand post popularity such as post vividness, interactivity, informational content, entertaining content, and the valance of comments [12]. Their results suggest that vivid and interactive brand posts may increase the number of likes given by the followers. Rishika et al. (2013) show that customer participation is significantly influenced by firms' social media efforts [37]. Dijkmans et al. (2015) find that company social media activities precedes perceptions of corporate reputation [38]. Thus, we propose the following hypothesis:

Hypothesis 2. Higher levels of firm social media engagement have a positive influence on firm popularity.

Though studies show that information seeking and emotional connection constitute the two strongest drivers behind social media use, it remains unclear which factor has a greater influence. Based on a survey, Baird and Parasnis (2011) showed that the two main reasons why consumers follow firms on social media sites are to receive 'discount' information and 'purchase' items while businesses believe that consumers primarily wish to 'learn about new products' and obtain 'general information' [39]. It suggests that consumers may put their information needs first.
However, some argue that when a firm is actively engaged with their followers on social media platforms, it increases its level of social connection with its users. Their followers might solicit other users connected to the firm to become followers [40]. This in turn have effect on attracting followers. In summing up both perspectives, we arrive at two competing hypotheses:

Hypothesis 3a. (Competing) Firm intrinsic characteristics have more predictive power than firm social media engagement on firm popularity

Hypothesis 3b. (Competing) Firm social media engagement have more predictive power than firm intrinsic characteristics on firm popularity.

\section{Data and Measures}

\subsection{Data}

In order to investigate firm social media popularity, we chose firms that public listed on American market as sample. Firstly, we compiled a list of publicly listed firms from US stock exchanges NYSE, AMEX, and NASDAQ in May 2015, In total there are 5,301 firms. Then we filtered firms that are thinly-traded out. Trading volume is a proxy which containing information about the disequilibrium dynamics of the markets [41]. It is an important factor that shows how investors treat the stocks. Thus, follow previous studies [42, 43, 44], we removed the firms that are thinly traded, i.e., whose monthly trading volume are less than 10,000 . Then we landed with 4,837 firms.

Secondly, the official Twitter accounts of these firms were identified. A few sources were used during identification: official firm websites, Google Knowledge Box, and Twitter Search. Two groups of students were hired to search for accounts independently, and then their results were compared by a third team. We ultimately identified 2,557 firms with official Twitter accounts.

Table 1 shows social media adoption rate based on different industry sectors. Overall, the average adoption rate of all firms is around 53\%. The highest adoption rate occurred in Retail Trade and Information sector, which is understandable. Because both sectors' main customers are consumers, which need social media to have a better connection with their consumers. On the other hand, industries which mainly make transactions with organizations, showed less interests on social media. The differences of adoption rate among industries provide evidences on how firms' intrinsic characteristics have influenced their management decisions, which in turn have impact on firm social media adoption. 
Table 1. Industry comparison

\begin{tabular}{l|l}
\hline Industry & \% of Firms Adopted Twitter \\
\hline Public Administration & 0.00 \\
Management of Companies and Enterprises & 0.18 \\
Other Services & 0.29 \\
Finance and Insurance & 0.36 \\
Mining, Quarrying, and Oil and Gas Extraction & 0.37 \\
Agriculture, Forestry, Fishing and Hunting & 0.38 \\
Transportation and Warehousing & 0.40 \\
Health Care and Social Assistance & 0.46 \\
Real Estate and Rental and Leasing & 0.47 \\
MEAN & $\mathbf{0 . 5 3}$ \\
Wholesale Trade & 0.54 \\
Manufacturing & 0.55 \\
Construction & 0.56 \\
Arts, Entertainment, and Recreation & 0.58 \\
Educational Services & 0.60 \\
Professional, Scientific, and Technical Services & 0.61 \\
Utilities & 0.62 \\
Administrative Services & 0.66 \\
Accommodation and Food Services & 0.67 \\
Retail Trade & 0.77 \\
Information & 0.77 \\
\hline
\end{tabular}

Twitter data were collected on Jun 1st, 2017. The number of followers, followings and tweets of each firm were collected accordingly.

Figure 1 illustrates the number of followers of the Top 10 most popular firms on Twitter. The results show that that Twitter (ticker: TWTR) itself is the most attractive firm with more than 60 million followers, which is more than 1.5 times the number of followers of the second most attractive firm, The New York Times(ticker: $N Y T$ ). Facebook (ticker: $F B$ ) and Google(ticker: $G O O G L$ ) have a similar number of followers at roughly 18 and 14 million and are the third and fourth most attractive firms. Starbucks (ticker: $S B U X$ ), which is followed by 12 million users, is the fifth most popular firm on Twitter. The remaining firms in the top 10 listing have a rather similar number of followers ranging between 4.9 to 11.3 million.

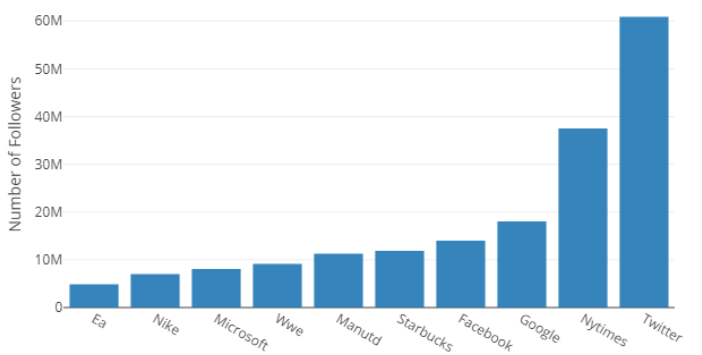

Figure 1. The number of followers of top $\mathbf{1 0}$ attractive firms

Information sector, where 6 out of top 10 firms are from, is indeed a celebrity industry. With only a $15 \%$ population of all firms, Information sector provides $45 \%$ and $25 \%$ of top $1 \%$ and top $5 \%$ popular firms.

Results shown on Table 1 and Figure 1 suggest that the industry that firms are belonged to has a great influence on how they adopt social media and how they are perceived on social media. In the following sections, we will have a more detailed analysis on other intrinsic characteristics that are associated with firm social media popularity.

\subsection{Measures}

Firm intrinsic characteristics. As discussed in Section 2.2, firm intrinsic characteristics are associated with users' information needs. Firms' stakeholder include their government, debt holders, customers and investors [45]. Considering that most social media users are general public users, in this paper we focus on firms customers and investors. Consumers' information needs toward a firm mostly concern information related to firm product quality and variance [39].

Regarding products, people mainly requires information such as the specifics of a product or whether there is a new product going to be announced. One of the commonly used indicator of changes in product is $R \& D$ costs. It shows how much a firm spent on developing new products or improving the quality of current products. Thus, $R \& D(R D)$ can be used as a measure of users' information needs.

To take account of customers' information needs on price variance, we chose the Inventory Turnover (TO) ratio. $T O$ is a measure of the number of times inventory is sold or used over a given time period [46]. It is highly correlated with product prices and variety levels [47], which both affect information needs. Firms presenting higher degrees of product variety understandably have higher levels of information asymmetry, meaning that their customers have more information needs. Product price is another obvious source of information needed by customers. Discount information is another important factor that users follow firms account [39]. Thus, we use $T O$ as another measure of information needs. $T O$ is calculated as the cost of goods sold or net sales divided by the average inventory value $(T O=$ Sales/Inventory).

Regarding on investors' information need, one possible indicator is trading volume (VOL). Social media not only connects businesses with their consumers, but also allows other stakeholders, such as investors to follow firms' accounts. In order to include the impact from investors, we choose trading volume, a proxy which containing information about the disequilibrium dynamics of the markets [41]. It is an important factor that shows how investors treat the stocks.

Another very important firm intrinsic characteristic that might influence the popularity of firms is industry. Firms from industries that focus on businesses 
customers are less likely to have more followers than those whose customers are public consumers. Our preliminary result (Table 1) echos the suggestion showing that firms in different industries have uneven social media adoption rates.

Firm social media engagement. The number of tweets a firm has sent ( $T W$ ) and the number of accounts it follows $(F O)$, are good measures of firm social media engagement.

Follow other accounts and frequently sending tweets demonstrate the firms is real and accessible. Chen (2011) found that the frequency of tweeting and the number of replies given have mediating effects on Twitter users and satisfy a need for connection [23]. Thus, the more tweets firms send out, the more their consumers will feel connected to them. Similarly, the number of users a firm follows has a positive impact on its social media community [40], because when a firm follows people who have followed them, it will boost social connections between itself and these users. Thus, we use the number of accounts that a firm follows $(F O)$ and the number of tweets a firm has sent $(T W)$ as two measures of social media users' emotional needs.

Control variables. Firm size is an important factor that might influence the number of followers a firm has. Large firms typically attract more consumers and have more stakeholders than smaller firms. Thus, we use market value $(M V)$ as our first control variable. Furthermore, we also normalized $F A N S, R D, V O L$, $F O$, and $T W$ by dividing those variables by $M V$ to take out the effect of firm size. The second control variable is Selling, General, \& Administration ( $S G \& A$ ) costs, which is a proxy of a firm's marketing costs. Higher marketing costs denote higher amounts spent on advertising and social media marketing, which may result in more consumers and followers. To reduce firm size bias and the problem of multicollinonary in the model, we use SGAR (SG\&A/Sales) as our control variable.

Dummy variables were introduced to detect differences among industries which are not explained by other variables. The firms were grouped and classified by NAICS classification system. The NAICS scheme employs a six-digit code. We adopted the highest level classification, 2-digits, which designate the largest business sector. In total there are 20 industry sectors. None of the three firms from Public Administration sector has a Twitter account. We also excluded the sectors that have less than 10 firms to reduce the bias (Three sectors and 10 firms were removed from the dataset). Thus, 16 industry sectors remained.

The following model was used to test the impact of firm intrinsic characteristics and social media engagement factors on their popularity. As discussed, the number of followers a firm has $(F A N S)$ was chosen to represent the level of firm social media popularity.

$$
\begin{array}{r}
F A N=\alpha+\beta_{1} M V+\beta_{2} S G A R \\
+\beta_{3} R D+\beta_{4} V O L+\beta_{5} T O \\
+\beta_{6} F O+\beta_{7} T W \\
+\beta_{8} \text { Dummy }
\end{array}
$$

Accounting data of all firms from 2011 Quarter 1 to 2016 Quarter 4 were collected from the COMPUSTAT database. To consistent with social media data, firms without financial data for between 2015 and 2016 were eliminated from the sample, leaving us with 1,995 firms to examine.

Table 2 presents descriptive statistics. It demonstrates that the average number of followers of all firms is 165,076 , with a very high $(1,777,313)$ standard deviation, indicating public attraction were paid unevenly. The data also showed that the number of

\begin{tabular}{|c|c|c|c|c|c|c|c|c|c|}
\hline & Mean & Std & FANS & FOS & TWS & MV & SGAR & $\mathrm{RD}$ & TO \\
\hline FANS & 165076 & 1777313 & & & & & & & \\
\hline FOS & 2595.15 & 14508 & $0.097 * * * *$ & & & & & & \\
\hline TWS & 10517.3 & 52732.54 & $0.140^{* * * *}$ & $0.332^{* * * *}$ & & & & & \\
\hline MV & 8719.17 & 26919.65 & $0.181^{* * * *}$ & $0.049^{*}$ & $0.119 * * *$ & & & & \\
\hline SGAR & 0.78 & 7.33 & -0.004 & -0.009 & -0.013 & -0.021 & & & \\
\hline RD & 79.72 & 393.31 & $0.123^{* * * *}$ & 0.047 & $0.061^{*}$ & $0.596^{* * * *}$ & -0.016 & & \\
\hline TO & 9.7 & 34.65 & 0.02 & 0.016 & 0.039 & 0.009 & -0.016 & -0.021 & \\
\hline VOL & 359369.6 & 1076667 & $0.173^{* * * *}$ & $0.082^{* * * *}$ & $0.109^{* * *} *$ & $0.527^{* * * *}$ & -0.019 & $0.610^{* * * * *}$ & 0.008 \\
\hline
\end{tabular}
followers $(F A N S)$ is significantly related with most of control and independent variables.

Table 2. Descriptive statistics

To depict the distribution of attention paid on firms, we compared the median value of each measure between a top $1 \%$ and an average firm (Figure 2). Again, it showed that users' attention are paid quite unevenly to the firms, where top $1 \%$ celebrity firms on Twitter have 1425 times more followers than the average firms.

Interestingly the results showed a disparity picture on different factors too. Top $1 \%$ firms have sent 12 times more tweets, have 10 times more Market Value than the average firm. However, the biggest differences between the popular firms and average firms is their $R \& D$ spent. Popular firms spent 35 times more money on $R \& D$. The results suggest that social media users are interested in new products or product developments. The smallest differences, on the other hand, occurred on $S G A R$, which showed that top firms and average firms spent a similar percentage amount on marketing expenses. 

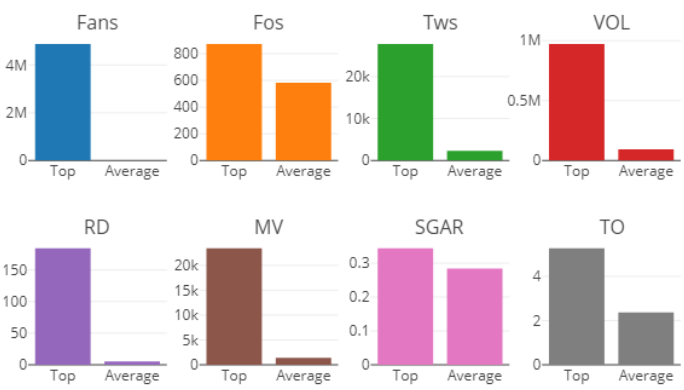

Figure 2. Comparison between a top $1 \%$ firm and an average firm

Figure 3 illustrates the median number of followers normalized by their market value. It shows that after taking out the effect of market size, The median number of the follower/market value ratio among all sectors is 2.90 .

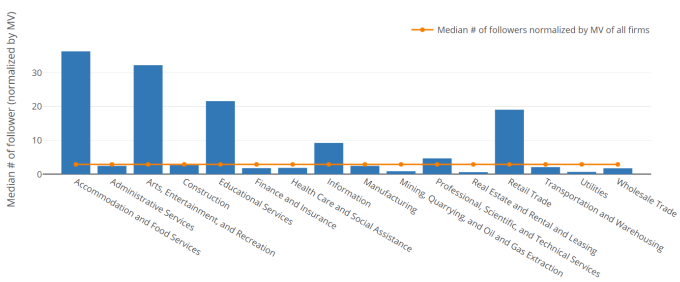

Figure 3. Number of followers normalized by market value

It can be found that there is a wide dispersion of public attention paid on different industries. Among the six sectors that have a higher-than-average ratio, the numbers range from 4.67 to 36.31 . The results again showed that industry has a huge impact on the popularity of firms. Most sectors that having higher than average follower/market-value ratios are the ones mainly focus on consumers rather than businesses customers.

\section{Results}

To compare the effect of firm intrinsic characteristics and their social media engagement factors, we conducted multiple hierarchical regressions. A series of ordinary least squares (OLS) regressions was performed to assess whether the proposed firm characteristics are predictive factors of the degree of firm celebrity. In these analyses, $M V$ and $S G \& A$ were included in the baseline model (Model 0). Model 1 included firms' intrinsic characteristics, i.e., $R D, T O$ and $V O L$, in addition to the aforementioned control variable, to test Hypothesis 1. Industry dummy variables were added in Model 2 to compare their associations with firm social media popularity. Finally, $F O$ and $T W$ were added to the regression equation in Model 3 to test Hypotheses 2 and 3 .

Tables 3 shows the regression results of all models. All variables are logarithms transformed and the results are based on White Robust Standard Errors [48]. $F A N S, R D, V O L, F O$, and $T W$ were normalized by $M V$.

Table 3. Hierarchical regression analysis on the

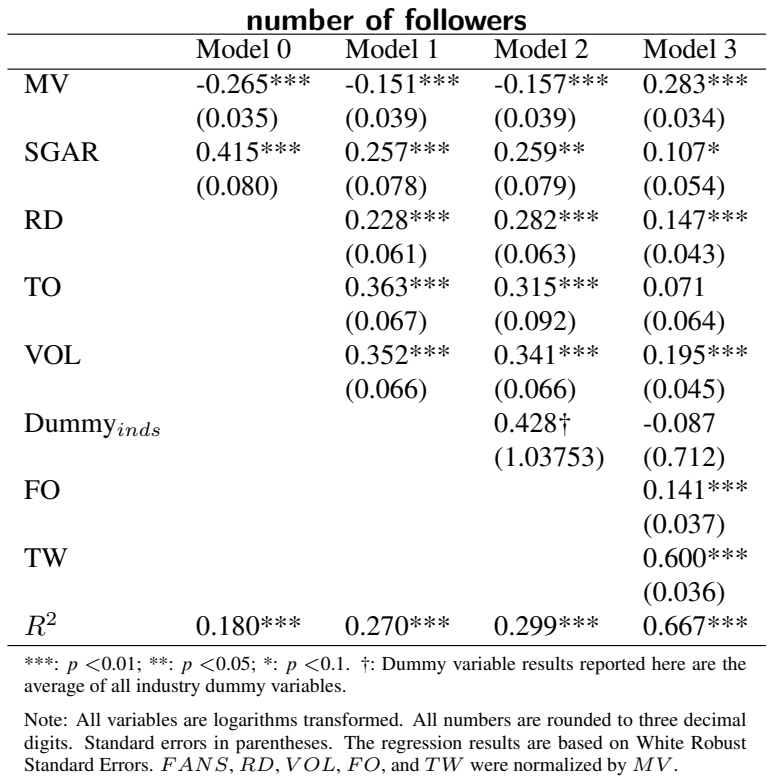

Model 0: Control Variables For the baseline model, both $M V(\beta=-0.265, p<.01)$ and $S G A(\beta=$ $.415, p<.01)$ appeared to have positive effects on firm popularity $\left(R^{2}=0.180\right)$. Because we have take the effect of firm size of the dependent variable, FANS, the negative effect of $M V$ is understandable. As expected, $S G A R$, which denotes to firm marketing costs has a positive association with firm popularity.

Model 1: Firm Intrinsic Characteristics. In Model 1, we added three characteristics variables: $R \& D$, $T O$, and VOL. Overall, the intrinsic characteristics explained an additional $9 \%$ of the variance in the degree of firm celebrity. As was predicted, $R \& D(\beta=$ $0.228, p<.001)$ appeared to be a significant predictor of firm popularity. TO $(\beta=0.363, p<.001)$ was found to have a stronger effect on firm popularity than $R \& D$, whereas, $V O L(\beta=0.352, p<.001)$ showed a significant relationship with firm popularity as well. In turn, the results provide directional support for Hypothesis 1 of a positive relationship between the three characteristics and firm social media popularity. 
Model 2: Industry Impact. In Model 2, industry dummy variables were introduced to detect any differences which cannot explained by the other firm intrinsic characteristics. Because it is necessary to use one less dummy variable than the number of categories into which the data are divided [49], we use 15 dummy variables and omitted was Accommodation and Food Services. Thus, we only report the average beta and standard errors. The result shows that after adding the industry dummy variables, it has increased the $R^{2}$ of the regression by $2.9 \%$, which indicating that industry has impact on firm popularity.

Model 3: Firm Social Media Engagement. The inclusion of social media engagement has a significant effect, adding an additional $36.8 \%$ of the variance in the degree of firm celebrity. The results show that both $F O$ and $T W$ have significant and positive effects on firm popularity, thereby providing support for Hypothesis 2 . In addition, $T W$ had the strongest effect on firm popularity $(\beta=0.600, p<.01)$ among all the variables. $\operatorname{VOL}(\beta=0.195, p<.01)$ and $R \& D(\beta=0.147, p<$ $.05)$ had similar effects on firm celebrity. $F O(\beta=$ $0.141, p<.01$ ) had the least significant effect relative to the other variables. Moreover, the effect of $T O$ had vanished. These results show that firm social media engagement have a greater impact on their popularity compared to the nature of the firms. Hypothesis $3 \mathrm{~b}$ is thus supported.

\subsection{Robustness Check}

Our White's Lagrange Multiplier Test of the models revealed the presence of heteroskedasticity $(p<0.1)$, and thus we used robust standard errors to correct for heteroskedasticity [48]. Furthermore, to evaluate multicollinearity between the variables, we calculated variance inflation factors $(V I F s)$. As all of the VIF values were found to be less than 6 (below the threshold value of 10), our sampled firms do not denote significant multicollinearity effects.

Social media platforms still occupy a developing stage, as a firm may acquire more followers each day. Thus, to show that our results are independent of the specific date of our data collection, we used data collected on Jan 1st, 2017 (five month earlier than original data collection) to run the regression models again. Table 4 shows the same trends as those for data collected on Jun 1st, 2017.

Furthermore, we tested the models based on a recent financial dataset that only included financial factors for between 2015 and 2016 rather than those for 2011 to 2016 to examine the effects of time on the results. The
Table 4. Regression results with data collected on

\begin{tabular}{|c|c|c|c|c|}
\hline \multicolumn{5}{|c|}{ Jan 1st 2017} \\
\hline & Model 0 & Model 1 & Model 2 & Model 3 \\
\hline \multirow[t]{2}{*}{ MV } & $-0.292 * * *$ & $-0.158^{* * * *}$ & $-0.163 * * *$ & $0.299 * * *$ \\
\hline & $(0.037)$ & $(0.041)$ & $(0.041)$ & $(0.034)$ \\
\hline \multirow[t]{2}{*}{ SGAR } & $0.408 * * *$ & $0.234 * *$ & $0.241 * *$ & $0.109^{*}$ \\
\hline & (0.084) & $(0.081)$ & $(0.083)$ & $(0.055)$ \\
\hline \multirow[t]{2}{*}{$\mathrm{RD}$} & & $0.278 * * *$ & $0.343 * * *$ & $0.150 * * *$ \\
\hline & & $(0.064)$ & $(0.066)$ & $(0.044)$ \\
\hline \multirow[t]{2}{*}{ TO } & & $0.355 * * *$ & $0.280^{* *}$ & 0.054 \\
\hline & & $(0.071)$ & $(0.096)$ & $(0.064)$ \\
\hline \multirow[t]{2}{*}{ VOL } & & $0.386^{* * *}$ & $0.371 * * *$ & $0.197 * * *$ \\
\hline & & $(0.069)$ & $(0.069)$ & $(0.046)$ \\
\hline \multirow[t]{2}{*}{ Dummy $_{\text {inds }}$} & & & 0.377 & -0.177 \\
\hline & & & (1.088) & $(0.723)$ \\
\hline \multirow[t]{2}{*}{ FO } & & & & $0.142 * * *$ \\
\hline & & & & $(0.037)$ \\
\hline \multirow[t]{2}{*}{ TW } & & & & $0.635^{* * *}$ \\
\hline & & & & $(0.037)$ \\
\hline$R^{2}$ & $0.183 * * *$ & $0.278 * * *$ & $0.308 * * *$ & $0.696^{* * *} *$ \\
\hline \multicolumn{5}{|c|}{$\begin{array}{l}* * *: p<0.01 ; * *: p<0.05 ; * ;<<0.1 \text { * } ; \text { ** Dummy variable results reported here are the } \\
\text { average of all industry dummy variables. }\end{array}$} \\
\hline
\end{tabular}

results (Table 5) show similar trends to those of the original models. The effect of $T W$ and $R \& D$ remains as the two strongest factor,

Table 5. Regression with the most recent two year's

\begin{tabular}{|c|c|c|c|c|}
\hline \multicolumn{5}{|c|}{ financial data } \\
\hline & Model 0 & Model 1 & Model 2 & Model 3 \\
\hline \multirow[t]{2}{*}{ MV } & $-0.286^{* * *}$ & $-0.189 * * *$ & $-0.195 * * *$ & $0.266^{* * *}$ \\
\hline & $(0.032)$ & $(0.039)$ & $(0.039)$ & $(0.035)$ \\
\hline \multirow[t]{2}{*}{ SGAR } & $0.340 * * *$ & $0.224 * *$ & $0.209 * *$ & 0.090 \\
\hline & $(0.074)$ & $(0.074)$ & $(0.075)$ & $(0.052)$ \\
\hline \multirow[t]{2}{*}{$\mathrm{RD}$} & & $0.275 * * *$ & $0.290 * * *$ & $0.137 * *$ \\
\hline & & $(0.061)$ & $(0.062)$ & $(0.043)$ \\
\hline \multirow[t]{2}{*}{ TO } & & $0.330 * * *$ & $0.263 * *$ & 0.061 \\
\hline & & $(0.060)$ & $(0.080)$ & $(0.056)$ \\
\hline \multirow[t]{2}{*}{ VOL } & & $0.204 * *$ & $0.198 * *$ & 0.160 *** \\
\hline & & $(0.062)$ & $(0.063)$ & $(0.043)$ \\
\hline \multirow[t]{2}{*}{ Dummy $_{\text {inds }}$} & & & 0.538 & -0.250 \\
\hline & & & $(1.00)$ & $(0.691)$ \\
\hline \multirow[t]{2}{*}{ FO } & & & & $0.124 * * *$ \\
\hline & & & & $(0.037)$ \\
\hline \multirow[t]{2}{*}{ TW } & & & & $0.621 * * *$ \\
\hline & & & & $(0.036)$ \\
\hline$R^{2}$ & $0.200 * * *$ & $0.273 * * *$ & $0.282 * * *$ & $0.661 * * *$ \\
\hline \multicolumn{5}{|c|}{$\begin{array}{l}* * *: p<0.01 ; * *: p<0.05 ; *: p<0.1 \text { * } \dagger \text { : Dummy variable results reported here are the } \\
\text { average of all industry dummy variables. }\end{array}$} \\
\hline
\end{tabular}

\section{Discussion and conclusions}

\subsection{Discussion}

Being popular on social media has been proven to bring management, marketing and finance benefits to 
firms [9, 19]. However, what relates to firms level of popularity remains less understood. This paper first explores which are celebrity firms and then discusses what associated with their popularity. Our study reveals a disparity whereby the median of top $1 \%$ most popular firms on Twitter generating 1,425 times followers as many as than the median number of followers of all firms. Such a contrast is quite striking, considering the median market value of the $1 \%$ biggest firms is only as 10 times much as all firms. Furthermore, the biggest differences between popular and average firm is that how much they spent on their research and development costs. Top $1 \%$ popular firms spent a surprising 35 times more money on $R \& D$ than average firms. Taking that nearly half of top $1 \%$ popular firms are from Information industry, it is reasonable to suggest that technology firms, such as, Google and Facebook, who have paid a large amount money on $R \& D$, are somehow 'born-to-be' social media celebrities.

Social media allows users to follow one another and the choice of this following action reflect the users' needs. The two reasons that social media users might follow a firm's account are: information needs and emotional needs. One of the most important reasons for users to follow firm social media account is to acquire firm related information, e.g., product quality or discount. It is mainly decided by the products a firm sells, the variety of product lines, or the frequency the firm update their products or prices. Specifically, information needs reflects firm intrinsic characteristics. Emotional needs, on the other hand, pertains firms' social media engagement. One of the roles of social media is to be 'social' with others. People who using social media want to be connected with firms or become a member of brand communicate [32]. Such needs cannot be fulfilled by firm intrinsic characteristics, but can be satisfied by firm social media engagement. A firm sending more tweets and replying users comments frequently could make users feel the firms is real and accessible $[12,34,35,36]$. Thus, it may attract more followers than a less active firm.

Previsions studies usually focus on firm social media engagement. Our paper examined both needs based on U.S. public listed firms and discovered that both firm intrinsic characteristics and firm social media engagement have impact on firm social media popularity. Specifically, there are intrinsic popular traits. Firms with higher R\&D costs, a higher inventory turnover ratio, and high trading volumes are considered to have a higher level of celebrity. Moreover, firms in certain industries may attract more followers than the ones in other industries. Consistence with previous studies [38], our paper also confirmed that the level of firm social media activities, such as the number of tweets has sent and the number of accounts the firm followed, has positive association with the level of firm social media popularity.

Furthermore, our findings showed that emotional needs play a more important role than information needs. This indicates that though social media users may be attracted to firms' intrinsic characteristics, they value social media interactions more than information acquisition. The results revealed that a one percent increase in the number of tweets a firm has sent would yield a $0.6 \%$ increase in its number of followers, whereas a one percent increase in research $\&$ development costs and trading volumes would only yield $0.147 \%$ and $0.195 \%$ change in the number of followers respectively.

\subsection{Implications}

By demonstrating that both firm intrinsic characteristics and social media engagement have impact on firm celebrity, our research offers several implications. First and foremost, this study makes a theoretical contribution to the literature by showing that some firms have intrinsic features that making them popular on social media. This means when analyzing the effect of firm social media activities, their intrinsic characteristics should be considered.

Moreover, our results showed that emotional connection with social media users are important than firm intrinsic characteristics. Users attach different weights to information and emotional needs. In other words, companies must be aware of the importance of their social media engagements. Considering the huge difference between the costs of increasing marketing value or research \& development spent and the cost of sending posts and follow other accounts, it is very efficient for firms to gain popularity by engaging with users on social media. Firm managers can take advantage of social media engagements to increase firm popularity levels and to eventually enjoy marketing and management benefits.

However, with the further withdraw of traditional mass media and the diminishing marginal returns of social engagement, it is possible firms' intrinsic characteristics might play a bigger role in future. Such a trend could be revealed, given bigger time frame.

\subsection{Limitations and Future Research}

As with all studies, this paper also has its limitations. In examining firms' social media engagements, this paper did not discuss the content that firms send, e.g., whether firms send Tweets relevant to their business 
or not. Though it is reasonable to assume that most firms would mostly focus on sending business-related information on social media platforms, future studies could involve text analyses on the quality of Tweets sent.

Overall, this paper offers a deeper understanding of how firms' intrinsic characteristics influence their popularity levels in relation to all firms and social media users. However, there are other factors that may have impact on users' attention, e.g., price variances, different product types (high value and low value items), and the risk of the purchase. Thus, future studies should classify firms by products delivered, customer bases, or industries to develop a stronger understanding of different groups involved.

Despite these limitations, this study contributes to a better understanding of the portrait of popular firms and discovers the information and emotional needs from social media users. Moreover, we showed that firms' social media engagement is more important than their intrinsic characteristics. The findings provide evidence that companies should be more engaged to social media activities and optimizing their effectiveness. From a firm's perspective, social media seems more social than media, for now.

\section{Acknowledgments}

This research is supported by the National Natural Science Foundation of China [71401139,71671141], the Fundamental Research Funds for the Central Universities [JBK120505], Financial Intelligence and Financial Engineering Key Laboratory of Sichuan Province, and Key Lab of Internet Natural Language Processing of Sichuan Provincial Education Department.

\section{References}

[1] Y. Yu, W. Duan, and Q. Cao, "The impact of social and conventional media on firm equity value: A sentiment analysis approach," Decision Support Systems, vol. 55, pp. 919-926, Dec. 2013.

[2] Y.-m. Li and Y.-1. Shiu, "A diffusion mechanism for social advertising over microblogs," Decision Support Systems, vol. 54, no. 1, pp. 9-22, 2012.

[3] F. Li and T. C. Du, "Listen to me - Evaluating the Influence of Micro-Blogs," Decision Support Systems, vol. 62, pp. 119-130, 2014.

[4] A. M. Kaplan and M. Haenlein, "The early bird catches the news: Nine things you should know about micro-blogging," Business Horizons, vol. 54, pp. 105-113, Mar. 2011.

[5] V. Rindova, T. Pollock, and M. Hayward, "Celebrity firms: The social construction of market popularity," Academy of Management Review, vol. 31, no. 1, pp. 50-71, 2006.
[6] M. D. Pfarrer, T. G. Pollock, and V. P. Rindova, "A tale of two assets: The effects of firm reputation and celebrity on earnings surprises and investors' reactions," Academy of Management Journal, vol. 53, pp. 1131-1152, Oct. 2010.

[7] A. J. O'Connor, "The Power of Popularity: An Empirical Study of the Relationship Between Social Media Fan Counts and Brand Company Stock Prices," Social Science Computer Review, vol. 31, no. 2, pp. 229-235, 2012.

[8] E. Blankespoor, G. S. Miller, and H. D. White, "The Role of Dissemination in Market Liquidity: Evidence from Firms' Use of Twitte," The Accounting Review, vol. 89, pp. 79-112, Jan. 2014.

[9] R. M. Alexander and J. K. Gentry, "Using social media to report financial results," Business Horizons, vol. 57, pp. 161-167, mar 2014.

[10] L. Liu, Q. Li, Y. Xu, and Y. Zhang, "Firm celebrity, reputation and performance: A social media perspective," in PACIS 2014 Proceedings, p. 14, 2014.

[11] B. Cruz, J. Mendelsohn, and C. M. Biley, "Why Social Media Matters to Your Business," tech. rep., Chadwick Martin Bailey, 2010.

[12] L. De Vries, S. Gensler, and P. S. H. Leeflang, "Popularity of Brand Posts on Brand Fan Pages: An Investigation of the Effects of Social Media Marketing," Journal of Interactive Marketing, vol. 26, no. 2, pp. 83-91, 2012.

[13] K. Heinonen, "Consumer activity in social media: Managerial approaches to consumers' social media behavior," Journal of Consumer Behaviour, vol. 10, pp. 356-364, 2011.

[14] K. Lee, B. Lee, and W. Oh, "Thumbs Up, Sales Up? The Contingent Effect of Facebook Likes on Sales Performance in Social Commerce," Journal of Management Information Systems, vol. 32, no. 4, pp. $109-143,2016$

[15] S. Chung, A. Animesh, K. Han, and A. Pinsonneault, "Firms' Social Media Efforts, Consumer Behavior, and Firm Performance," in Thirty Fifth Internaional Conference on Information Systems, p. 49, 2014.

[16] K. Goh, C. Heng, and Z. Lin, "Social Media Brand Community and Consumer Behavior: Quantifying the Relative Impact of User- and Marketer-Generated Content," Information Systems Research, vol. 24, no. March 2013, pp. 88-107, 2013.

[17] L. Hollebeek, M. S. Glynn, and R. J. Brodie, "Consumer brand engagement in social media: Conceptualization, scale development and validation," Journal of Interactive Marketing, vol. 28, no. 2, pp. 149-165, 2014.

[18] T. D. Hubbard, T. Pollock, M. Pfarrer, and V. P. Rindova, "Safe bets or hot hands? how status and celebrity influence strategic alliance formations by newly-public firms," Academy of Management Journal, p. amj.2016.0438, nov 2018. Forthcoming.

[19] A. M. Kaplan and M. Haenlein, "Users of the world, unite! The challenges and opportunities of Social Media," Business Horizons, vol. 53, pp. 59-68, Jan. 2010.

[20] E. Katz, J. G. Lumler, and M. Gurevitch, "Uses and Gratifications Research," Public Opinion Quarterly, vol. 37, no. 4, pp. 509-523, 1973. 
[21] W. J. Severin and J. W. Tankard, Communication Theories: Origins, Methods and Uses in the Mass Media (5th Edition). Allyn \& Bacon, June 2000.

[22] D. McQuail, Mass communication theory: an introduction. Sage Publications, 1994.

[23] G. M. Chen, "Tweet this: A uses and gratifications perspective on how active Twitter use gratifies a need to connect with others," Computers in Human Behavior, vol. 27, no. 2, pp. 755-762, 2011.

[24] E. Kim, Y. Sung, and H. Kang, "Brand followers' retweeting behavior on Twitter: How brand relationships influence brand electronic word-of-mouth," Computers in Human Behavior, vol. 37, pp. 18-25, 2014.

[25] F. C. Tseng, H. C. Huang, and C. I. Teng, "How Do Online Game Communities Retain Gamers? Social Presence and Social Capital Perspectives," Journal of Computer-Mediated Communication, vol. 20, pp. 601-614, 2015.

[26] S. Valenzuela, N. Park, and K. F. Kee, "Is There social capital in a social network site?: Facebook use and college student's life satisfaction, trust, and participation1," Journal of Computer-Mediated Communication, vol. 14, no. 4, pp. 875-901, 2009.

[27] T. F. Stafford, M. R. Stafford, and L. L. Schkade, "Determining uses and gratifications for the Internet," Decision Sciences, vol. 35, no. 2, pp. 259-288, 2004.

[28] Q. Li, X. Guo, and X. Bai, "Weekdays or weekends: Exploring the impacts of microblog posting patterns on gratification and addiction." Information \& Management, Forthcoming, 2016.

[29] L. R. Men and W.-H. S. Tsai, "Beyond liking or following: Understanding public engagement on social networking sites in China," Public Relations Review, vol. 39, no. 1, pp. 13-22, 2012.

[30] N. Park, K. F. Kee, and S. Valenzuela, "Being Immersed in Social Networking Environment: Facebook Groups, Uses and Gratifications, and Social Outcomes," Cyberpsychology \& Behavior, vol. 12, no. 6, pp. 729-733, 2009.

[31] J. Gallu, "SEC approves using facebook, twitter for company disclosures," 2013. Bloomberg Report 03 Apr 2013.

[32] S. Han, J. Min, and H. Lee, "Antecedents of social presence and gratification of social connection needs in SNS: A study of Twitter users and their mobile and non-mobile usage," International Journal of Information Management, vol. 35, no. 4, pp. 459-471, 2015.

[33] H. Khobzi, R. Y. K. Lau, and T. C.-H. Cheung, "Consumers' Sentiments and Popularity of Brand Posts in Social Media: The Moderating Role of Up-votes," in Proceedings of the 50th Hawaii International Conference on System Sciences, pp. 3905-3914, 2017.

[34] T. Correa, A. W. Hinsley, and H. G. de Zúñiga, "Who interacts on the Web?: The intersection of users' personality and social media use," Computers in Human Behavior, vol. 26, pp. 247-253, mar 2010.

[35] I. P. Cvijikj and F. Michahelles, "Online engagement factors on Facebook brand pages," Social Network Analysis and Mining, vol. 3, no. 4, pp. 843-861, 2013.

[36] K. Zhang, M. Benyoucef, and S. J. Zhao, "Consumer participation and gender differences on companies' microblogs: A brand attachment process perspective," Computers in Human Behavior, vol. 44, pp. 357-368, 2015.
[37] R. Rishika, A. Kumar, R. Janakiraman, and R. Bezawada, "The Effect of Customers' Social Media Participation on Customer Visit Frequency and Profitability: An Empirical Investigation," Information Systems Research, vol. 24, pp. 108-127, Dec. 2013.

[38] C. Dijkmans, P. Kerkhof, A. Buyukcan-Tetik, and C. J. Beukeboom, "Online conversation and corporate reputation: A two-wave longitudinal study on the effects of exposure to the social media activities of a highly interactive company," Journal of Computer-Mediated Communication, vol. 20, no. 6, pp. 632-648, 2015.

[39] C. H. Baird and G. Parasnis, "From social media to social customer relationship management," Strategy \& Leadership, vol. 39, no. 5, pp. 30-37, 2011.

[40] M. Zhang, B. J. Jansen, and A. Chowdhury, "Business engagement on Twitter: A path analysis," Electronic Markets, vol. 21, no. 3, pp. 161-175, 2011.

[41] C. G. Lamoureux and W. D. Lastrapes, "Heteroskedasticity in Stock Return Data: Volume versus GARCH Effects," The Journal of Finance, vol. 45, no. 1, pp. 221-229, 1990

[42] A. C. M. Leung, A. Agarwal, P. Konana, and A. Kumar, "A Study of Search Attention and Stock Returns Cross Predictability Full paper," in Twenty-first Americas Conference on Information Systems, pp. 1-12, 2015.

[43] M. Nimalendran and G. Petrella, "Do 'thinly-traded' stocks benefit from specialist intervention?," Journal of Banking and Finance, vol. 27, no. 9, pp. 1823-1854, 2003.

[44] D. Easley, N. M. Kiefer, and M. O. Hara, "Liquidity , Information , and Infrequently Traded Stocks," The Journal of Finance, vol. 51, no. 4, pp. 1405-1436, 1996.

[45] E. Freeman, D. L. Reed, R. E. Freeman, D. L. Reed, E. Freeman, and D. L. Reed, "Stockholders and stakeholders: A new perspective on corporate governance," California Management Review, vol. 25, no. 3, pp. 88-106, 1986.

[46] M. C. Rao and K. P. Rao, "Inventory turnover ratio as a supply chain performance measure," Serbian Journal of Management, vol. 4, no. 1, pp. 41-50, 2009.

[47] V. Gaur, M. L. Fisher, and A. Raman, "An Econometric Analysis of Inventory Turnover Performance in Retail Services," Management Science, vol. 51, no. 2, pp. 181-194, 2005.

[48] H. White, "A Heteroskedasticity-Consistent Covariance Matrix Estimator and a Direct Test for Heteroskedasticity," Econometrica, vol. 48, no. 4, pp. 817-838, 1980.

[49] K. C. Brown, "The Significance of Dummy Variables in Multiple Regression Involving Financial and Economic Data," Journal of Finance, vol. 23, no. 3, pp. 515-517, 1968. 